\title{
The Lasker Awards: motors take centre stage
}

\author{
Michael Sheetz, James Spudich and Ronald Vale have been awarded the prestigious Albert Lasker Basic Medical \\ Research Award for their work on cytoskeletal motors. Nature Cell Biology joins the scientific community in \\ congratulating the awardees and in celebrating the importance of basic research in furthering scientific endeavour.
}

Albert Davis Lasker and his wife Mary Woodard-Lasker established the Albert and Mary Lasker Foundation in 1942 with the aim of fostering the advancement of biomedical research directed towards understanding the basis of human disease. In 1945, the Foundation initiated what was to become one of the highest honours in biomedical science, the Lasker Awards Program, recognizing the efforts of researchers and physicians who have advanced our knowledge and ability to diagnose, treat or prevent disease, as well as the contributions of individuals to public health services. Since the awards' inception, the Lasker Foundation has honoured hundreds of scientists, with eighty-three Lasker recipients going on to receive the Nobel Prize.

Michael Sheetz, James Spudich and Ronald Vale have now joined the list of Lasker laureates, having jointly received the 2012 Albert Lasker Basic Medical Research Award for their "discoveries concerning cytoskeletal motor proteins, machines that move cargoes within cells, contract muscles, and enable cell movements"1.

Although the mechanism of action and the cellular functions performed by force-generating cytoskeletal motors, including their roles in intracellular trafficking, cell migration, cell division and muscle contraction, are now a fundamental part of cell biology, in the 1970s and 1980s they were still mostly a mystery. Following a postdoctoral fellowship under the guidance of Hugh Huxley, a pioneer of muscle contraction studies, James Spudich established his independent work at the University of California San Francisco (UCSF) and later at Stanford University on what was, at the time, the largely unchartered territory of myosin activity and function. A fortuitous crossing of paths occurred in 1982, when Michael Sheetz joined the Spudich laboratory on sabbatical from his own independent research at the University of Connecticut Health Center. Working together, Spudich and Sheetz demonstrated myosin movement on actin filaments using the Nitella axillaris alga as a model, and later established an in vitro reconstitution system that demonstrated the ability of purified myosin to move on purified actin filaments in the presence of adenosine triphosphate at rates consistent with those of muscle contraction. This seminal work was published in Nature in $1983^{2}$ and $1985^{3}$.

Spurred by the exciting work on myosin-based movement, Ronald Vale, then a graduate student at Stanford University, decided with Michael Sheetz to define the particle movement observed in squid axons. Their experiments at the Marine Biology Laboratory in Woods Hole led to a series of groundbreaking Cell publications in $1985^{4-8}$, which determined that axonal movement was not driven by myosin on actin filaments as they had anticipated, but was instead occurring on microtubules and was powered by a then-uncharacterized factor that they purified and named kinesin.
These initial efforts investigating myosin- and kinesin-powered motility, and the in vitro assays developed to characterize cytoskeletal motor activities, opened up new and fascinating avenues of research and have become a corner-stone of cell biology today. Following these key discoveries, Spudich went on to define many other aspects of myosin activity and function. Vale continued his work on molecular motors and their cellular roles in his independent research at UCSF, and Sheetz followed a varied research career ranging from motility studies to work on cell adhesion and mechanosensing at Columbia University and the Mechanobiology Institute in Singapore.

In honouring the early work of Sheetz, Spudich and Vale, the Lasker Foundation recognizes the significance of the cytoskeletal motor field in biology, and also the importance of understanding the principles underlying cellular motor function in human diseases in which such activities are deregulated. Indeed, the characterization of normal myosin and kinesin activity and function has served as the spring-board for studies on their impaired or aberrant action in disease, with the goal of developing therapies for heart conditions in the case of myosins, and neurological disorders and malignancy in the case of kinesins.

It should also be noted that the discoveries acknowledged by the Lasker Award and the subsequent scientific careers of the three awardees were the outcome of an inspired mix of cell and molecular biology, biochemistry and physics, among other disciplines, and are thus a testament to the importance of fostering multidisciplinary science. Moreover, as the three award recipients eloquently noted in their Lasker Award acceptance remarks, the motivating force during the exciting times of their initial research on motors was not only a thirst for discovery and a passion for science, but also a strong collaborative spirit. As a fundamentally creative and adventurous endeavour, science is often seen by outsiders as a solitary pursuit of inquiry and testing one's own ideas. However, the reality of a bustling laboratory reveals that teamwork, discussion and brainstorming, and a successful combination of different personalities, are just as important as individual intellect and drive. In that respect, the dedication, creativity and collaborative efforts of Sheetz, Spudich and Vale should be an inspiration to scientists everywhere.

1. www.laskerfoundation.org/awards/2012_b_description.htm 2. Sheetz, M. P. \& Spudich, J. A. Nature 303, 31-35 (1983).

3. Spudish, J. A., Kron, S. J. \& Sheetz, M. P. Nature 315, 584-586 (1985).

4. Vale, R. D., Schnapp, B. J., Reese, T. S. \& Sheetz, M. P. Cell 40, 449-454 (1985).

5. Schnapp, B. J., Vale, R. D., Sheetz, M. P. \& Reese, T. S. Cel/ 40, 455-462 (1985).

6. Vale, R. D., Schnapp, B. J., Reese, T. S. \& Sheetz, M. P. Cell 40, 559-569 (1985).

7. Vale, R. D., Reese, T. S. \& Sheetz, M. P. Cell 42, 39-50 (1985).

8. Vale, R. D. et al. Cell 43, 623-632 (1985). 